\title{
Development and validation of a prehospital prediction model for acute traumatic coagulopathy
}

\author{
Ithan D. Peltan ${ }^{1,2,3^{*}}$, Ali Rowhani-Rahbar ${ }^{4}$, Lisa K. Vande Vusse ${ }^{1}$, Ellen Caldwell ${ }^{1}$, Thomas D. Rea ${ }^{5}$, \\ Ronald V. Maier ${ }^{6}$ and Timothy R. Watkins ${ }^{1}$
}

\begin{abstract}
Background: Acute traumatic coagulopathy (ATC) is a syndrome of early, endogenous clotting dysfunction that afflicts up to 30\% of severely injured patients, signaling an increased likelihood of all-cause and hemorrhage-associated mortality. To aid identification of patients within the likely therapeutic window for ATC and facilitate study of its mechanisms and targeted treatment, we developed and validated a prehospital ATC prediction model.

Methods: Construction of a parsimonious multivariable logistic regression model predicting ATC — defined as an admission international normalized ratio >1.5 — employed data from 1963 severely injured patients admitted to an Oregon trauma system hospital between 2008 and 2012 who received prehospital care but did not have isolated head injury. The prediction model was validated using data from 285 severely injured patients admitted to a level 1 trauma center in Seattle, WA, USA between 2009 and 2013.

Results: The final Prediction of Acute Coagulopathy of Trauma (PACT) score incorporated age, injury mechanism, prehospital shock index and Glasgow Coma Score values, and prehospital cardiopulmonary resuscitation and endotracheal intubation. In the validation cohort, the PACT score demonstrated better discrimination (area under the receiver operating characteristic curve 0.80 vs. $0.70, p=0.032$ ) and likely improved calibration compared to a previously published prehospital ATC prediction score. Designating PACT scores $\geq 196$ as positive resulted in sensitivity and specificity for ATC of $73 \%$ and $74 \%$, respectively.
\end{abstract}

Conclusions: Our prediction model uses routinely available and objective prehospital data to identify patients at increased risk of ATC. The PACT score could facilitate subject selection for studies of targeted treatment of ATC.

Keywords: Acute traumatic coagulopathy, Trauma, Massive transfusion, Prediction model, Prediction score, Prehospital, Post-traumatic coagulopathy, Risk stratification

\section{Background}

Over the last 15 years, randomized trials have often failed to validate previously promising therapies for critically ill patients [1-4]. The study of traumatic injury, which was the cause over 130,000 deaths in the USA in 2013 and remains the leading killer of adults and children ages 1-44 years [5], is no exception. Uncontrolled

\footnotetext{
* Correspondence: ipeltan@uw.edu

'Division of Pulmonary and Critical Care Medicine, Department of Medicine, University of Washington School of Medicine, 1959 NE Pacific St, Box 356522, Seattle, WA 98195, USA

2Division of Pulmonary and Critical Care Medicine, Department of Medicine, Intermountain Medical Center, Salt Lake City, UT, USA

Full list of author information is available at the end of the article
}

hemorrhage and post-traumatic coagulopathy contribute to half of injury-related deaths [6], but interventions including recombinant factor VIIa [7-9] and balanced transfusion [10] have demonstrated no benefit in broad populations of injured patients. At least some such negative trials seem to occur because researchers, who are lacking tools to quickly identify the subset of patients with disease biology amenable to targeted therapy, are forced to include heterogeneous subject populations $[11,12]$.

The study of acute traumatic coagulopathy (ATC) poses particular challenges. Present in up to $30 \%$ of severely injured patients on emergency department (ED) arrival, ATC is an endogenous biologic syndrome 
contributing to, but distinct from, traumatic hemorrhage in general [13-16]. When defined as an international normalized ratio (INR) $>1.5$ on hospital admission, ATC is associated with a significantly increased risk-adjusted probability of not only all-cause and hemorrhageassociated mortality but also multiple organ failure and venous thromboembolism [13, 14, 17]. As most bleeding-related deaths occur early after injury, treatment to prevent or mitigate ATC also needs to begin quickly, potentially even in the prehospital setting. Diagnosis of ATC in this time frame, however, remains difficult: the conventional coagulation tests consistently linked to risk-adjusted outcomes are slow to return, but issues of validity, reliability, availability, and interpretation hinder broad implementation of otherwise promising point-of-care testing and viscoelastic measures [15, 18-21]. A simple, validated, predictive index using data available prior to ED admission to identify patients at high risk of ATC - as opposed to major hemorrhage more generally - could advance research and patient care by facilitating trial enrollment, efficient specimen collection, and, ultimately, targeted ATC treatment.

The only prehospital ATC prediction tool reported so far, the Coagulopathy of Severe Trauma (COAST) score, is based on vehicle entrapment, chest decompression by paramedics, and prehospital assessment of blood pressure, temperature, and abdominal/pelvic content injury [22]. As the score was not externally validated after development in a single-center Australian cohort, its generalizability is uncertain [23]. Marked differences in ambulance crew practice patterns in the USA also pose obstacles to the application of the COAST score in trauma settings within the USA.

In the current study, we developed and internally validated a prediction model for ATC using patient demographic information, injury characteristics, and clinical data available to providers before patients' arrival in the ED. We then externally validated our score in an independent trauma cohort and compared its performance to that of the COAST score.

\section{Methods}

\section{Derivation cohort}

To derive a multivariable model predicting ATC, we studied severely injured non-pregnant patients ages 18-89 years, who were entered in the Oregon Trauma Registry from 2008 to 2012 [24]. Trained staff at the 44 certified trauma centers in Oregon enter details of injured patients treated at their facility into the registry if they meet any of the following criteria: intensive care unit (ICU) admission $\leq 24$ hours from ED arrival; trauma team activation; prehospital trauma triage criteria met; surgical intervention; or injury severity score (ISS) $>8$ [25]. The registry excludes patients who die before ED arrival or who have isolated hip fracture after a groundlevel fall.

For model derivation, we used data from registry patients who met one or more of the following criteria for severe injury: death prior to discharge; admission directly from the initial trauma center ED to the ICU or operating room; or transfer from the initial ED to another state-certified trauma center ED followed by admission directly to the receiving facility ICU or operating room. Exclusion criteria included missing admission INR; initial care outside the trauma system; preadmission anticoagulant medication; blood transfusion during prehospital care; and no prehospital care. We also excluded patients with isolated burn or traumatic brain injury (no abbreviated injury score (AIS) $\geq 3$ except for the head) because coagulopathy in these conditions differs from polytrauma-associated ATC [26]. The Oregon Health Authority and University of Washington Institutional Review Boards approved the use of Oregon Trauma Registry data.

\section{Validation cohort}

We validated our model in a prospective cohort (Age of Transfused Blood and Lung Injury After Trauma Study) collected at Harborview Medical Center, a level 1 trauma center in Seattle, WA, USA [27]. Patients with blunt trauma, age $\geq 18$ years, admitted to the ICU from the ED (directly or via the operating room) between March 2010 and December 2013 were eligible for enrollment if transfused $\geq 1$ units of red blood cells within 24 hours of injury. Study exclusion criteria were acute respiratory distress syndrome on admission, isolated traumatic brain injury (radiologic brain injury without non-brain injury), transfusion $\leq 6$ months prior to admission, pregnancy, being in police custody, and expected survival $<24$ hours. The validation cohort excluded subjects on warfarin, with no prehospital care, or missing initial INR values. Trained research staff unaware of coagulopathy status collected data on patient characteristics, prehospital and ED care, and outcomes. The University of Washington Institutional Review Board approved the original study and granted exempt status to the current secondary analysis.

\section{Predictor and outcome definitions}

ATC was defined as an INR $>1.5$ on initial measurement in the first ED [17]. Potential ATC predictors identified a priori included patient and injury characteristics, and clinical and management data available before hospital arrival. Consistent with prior reports [28], we observed $\leq 1$ point difference between prehospital and ED GCS in $85 \%$ of subjects not intubated in the field. We therefore substituted initial ED values for missing prehospital GCS in subjects not intubated prehospital. GCS was analyzed 
as the difference between the measured GCS and a normal GCS (15) to provide a positive regression coefficient. Shock index - the ratio of the first prehospital heart rate to first prehospital systolic blood pressure (SBP) was considered elevated if $\geq 1$ [29]. Prehospital treatments included cardiopulmonary resuscitation, chest decompression (needle or tube thoracostomy), and endotracheal intubation or invasive airway. In addition to ISS and AIS [30], injury severity indicators included rollover motor vehicle crash, ejection or need for extrication from vehicle ("entrapment"), and death of another person on scene [31].

COAST scores were calculated as previously described (Table 1) [22]. As prehospital providers in the USA do not systematically evaluate abdominal/pelvic content injury [32], we applied a secondary definition - abdominal/pelvic AIS $\geq 1-$ used in the original description of the COAST score. Similarly, we employed the first ED temperature in place of the prehospital value [33].

\section{Missing data}

To minimize bias due to missing data, we performed multiple imputation based on chained equations to create 50 imputed datasets for both cohorts [34-36]. Missing values were imputed using predictive mean matching from three nearest neighbors for continuous variables [37] and logistic regression for binary variables. Imputation model variables (Additional file 1: Table S1) included missing and non-missing candidate predictors, hospital and coagulopathy outcomes, and other correlates of missing variables [38].

\section{Model development}

We constructed a multivariable ATC prediction model from prehospital variables in three steps: candidate predictor modeling, selection of a parsimonious final predictor set, and coefficient estimation. To minimize predictive bias and optimism, we ensured a $>10: 1$ ratio of outcome events to predictors entered in the model selection algorithm $[36,39,40]$. To achieve this ratio, we (1) discarded variables with $p$ values $>0.2$ in bivariable

Table 1 Coagulopathy of Severe Trauma (COAST) score

\begin{tabular}{lll}
\hline Variable & Value & Score \\
\hline Entrapment & Yes & 1 \\
Systolic blood pressure & $<100 \mathrm{mmHg}$ & 1 \\
& $<90 \mathrm{mmHg}$ & 2 \\
Temperature & $<35^{\circ} \mathrm{C}$ & 1 \\
& $<32^{\circ} \mathrm{C}$ & 2 \\
Chest decompression & Yes & 1 \\
Abdominal or pelvic content injury & Yes & 1 \\
Highest total possible & & 7
\end{tabular}

Reprinted from Mitra et al. with permission from Elsevier Ltd [22] analyses or missingness >25\%; (2) "forced" a variable based on the SBP into the final prediction model given its strong epidemiologic association with ATC and evidence for a causal mechanism underlying this association; and (3) created merged or collapsed candidate predictors (non-vehicular injury mechanism, shock index) when feasible and supported by bivariable analysis [23, 29, 36]. Continuous candidate predictors were evaluated without transformation as locally weighted scatterplot smoothing (LOWESS) plots revealed no major non-linearity in predictor/ INR relationships.

We adapted the "majority rules" approach to model selection described by Vergouwe et al. [41]. Within each imputed dataset, we evaluated all possible combinations of predictor variables using a best-subsets approach and a leaps-and-bounds algorithm adapted for logistic regression [42-44], choosing the model with the lowest Akaike information criterion. This likelihood-based measure of model fit penalizes larger models to reduce overfitting [45]. The final prediction model included predictors selected in $50 \%$ or more of the imputationderived models (Additional file 2: Figure S1). Coefficients for the final prediction model were obtained by combining regression coefficients from the 50 imputed datasets using Rubin's rules [46]. We created the Prediction of Acute Coagulopathy of Trauma (PACT) score by rounding raw model coefficients to one decimal place and multiplying by 100 .

\section{Evaluation of model performance}

We estimated model optimism in the multiply-imputed derivation cohort using bootstrap techniques [47]. After sampling with replacement for 1000 iterations, we performed the previously described model selection procedure on each bootstrap sample and compared model discrimination in the bootstrapped vs. original derivation cohort. The average difference for the 1000 bootstrapped samples is an estimate of the deterioration in model discrimination attributable to sampling bias. To formally test generalizability, we evaluated the discrimination and calibration of the PACT and COAST scores when applied to the validation cohort.

\section{Statistical analysis}

For bivariable analyses we employed the unpaired t test with unequal variance or the Mann-Whitney test for continuous variables and the chi-square or Fisher's exact test for categorical variables. Regression coefficients are reported with robust standard errors. Model discrimination measured using the area under the receiver operating characteristic curve (AUROC) is reported with 95\% confidence intervals and compared using the method of Delong et al. [48]. Model calibration was evaluated (1) graphically by plotting the observed versus predicted 
ATC probability across equal quantiles of predicted ATC risk and (2) using the Hosmer-Lemeshow goodness-offit statistic [49]. A $p$ value $>0.1$ for this statistic indicates no significant divergence of observed from predicted probabilities. As the 7-point COAST score cannot be divided into $>7$ quantiles, the primary PACT score calibration analysis also used 7 quantiles of predicted risk. For other tests, a $p$ value $\leq 0.05$ was considered significant. We used Stata version 14.0 (StataCorp LP, College Station, TX, USA) for all analyses and adhered to published guidelines for reporting of prediction models [50].

We performed two sensitivity analyses. We tested whether an alternate ATC definition adding partial thromboplastin time (PTT) $>60$ seconds to INR $>1.5$ altered our results. We also reevaluated the calibration of our model using deciles of ATC risk predicted by the PACT score.

\section{Results}

The model derivation cohort included 1963 patients enrolled in the Oregon Trauma Registry between 2008 and 2012 (Additional file 3: Figure S2). ATC was present in 115 patients $(5.9 \%)$. Coagulopathic patients were more severely injured, less likely to be injured while operating or riding in a motor vehicle, motorcycle or bicycle, more

Table 2 Demographic, injury and clinical characteristics of subjects included in the derivation cohort by coagulopathy status

\begin{tabular}{|c|c|c|c|c|c|}
\hline \multirow[b]{2}{*}{ Age } & \multicolumn{2}{|c|}{ INR $\leq 1.5(n=1848)$} & \multicolumn{2}{|c|}{ INR $>1.5(n=115)$} & \multirow{2}{*}{$\begin{array}{l}P \\
0.13\end{array}$} \\
\hline & 44.4 & $(18.3)$ & 47.4 & $(20.9)$ & \\
\hline Male sex & 1338 & $(72.5)$ & 84 & $(73.0)$ & 0.90 \\
\hline Race & & & & & 0.21 \\
\hline Black & 58 & $(3.2)$ & 4 & (3.5) & \\
\hline White & 1491 & $(82.2)$ & 86 & $(76.1)$ & \\
\hline Other & 264 & $(14.6)$ & 23 & $(20.4)$ & \\
\hline Hispanic & 185 & $(10.2)$ & 14 & $(12.4)$ & 0.50 \\
\hline Minutes from injury to ED arrival & 51 & $(39-70)$ & 49 & $(34-67)$ & 0.14 \\
\hline Mechanism of injury & & & & & 0.005 \\
\hline Motor vehicle crash & 611 & $(33.1)$ & 31 & $(27.0)$ & \\
\hline Motorcycle crash & 180 & $(9.7)$ & 5 & $(4.3)$ & \\
\hline Bicycle crash & 82 & $(4.4)$ & 1 & $(0.9)$ & \\
\hline Pedestrian struck & 106 & $(5.7)$ & 14 & $(12.2)$ & \\
\hline Fall & 404 & $(21.9)$ & 31 & $(27.0)$ & \\
\hline Other & 465 & $(25.2)$ & 33 & $(28.7)$ & \\
\hline \multicolumn{6}{|l|}{ Injury severity indicators } \\
\hline Ejection from vehicle & 65 & $(3.5)$ & 4 & $(3.5)$ & 1.0 \\
\hline Extrication & 129 & $(7.0)$ & 9 & $(7.8)$ & 0.73 \\
\hline Rollover motor vehicle crash & 150 & $(8.1)$ & 9 & $(7.8)$ & 0.91 \\
\hline \multicolumn{6}{|l|}{ First measured pre-hospital vital signs } \\
\hline Systolic blood pressure $(\mathrm{mmHg})$ & 131 & (27) & 119 & (29) & $<0.001$ \\
\hline Heart rate & 94 & (22) & 94 & (30) & 0.87 \\
\hline Respiratory rate & 20 & $(5.2)$ & 21 & $(6.8)$ & 0.33 \\
\hline First recorded non-intubated GCS & 15 & $(13-15)$ & 14 & $(9-15)$ & $<0.001$ \\
\hline \multicolumn{6}{|l|}{ Pre-hospital interventions } \\
\hline Cardiopulmonary resuscitation & 25 & $(1.4)$ & 16 & $(13.9)$ & $<0.001$ \\
\hline Chest decompression & 24 & $(1.3)$ & 5 & $(4.4)$ & 0.024 \\
\hline Intubation & 273 & $(14.8)$ & 44 & $(38.3)$ & $<0.001$ \\
\hline Initial ED temperature $\left({ }^{\circ} \mathrm{C}\right)$ & 36.4 & $(0.97)$ & 35.5 & $(2.12)$ & $<0.001$ \\
\hline Injury severity score & 16.8 & $(11.7)$ & 25.7 & $(1.3)$ & $<0.001$ \\
\hline Death before discharge & 122 & (6.6) & 53 & $(46.1)$ & $<0.001$ \\
\hline Hospital length of stay (days) & 6 & $(2-12)$ & 6 & $(1-19)$ & 0.38 \\
\hline
\end{tabular}

Values reported as median (SD), number (\%) or median (IQR). ED emergency department, GCS Glasgow Coma Score, INR international normalized ratio 
likely to undergo prehospital interventions and had lower prehospital SBP and GCS (Table 2).

Compared to the derivation cohort, the 285 subjects included in the validation cohort (Additional file 3: Figure S3) had a slightly higher ATC incidence (9.1\%), were more severely injured, and displayed greater physiologic derangements (Table 3). In-hospital mortality was $46 \%$ in subjects with ATC compared to $7 \%$ in subjects without ATC $(p<0.001)$ in the derivation cohort and $24 \%$ vs. $7 \%(p=0.001)$ in the validation cohort.

The final ATC prediction model included age, prehospital cardiopulmonary resuscitation (CPR) and intubation, prehospital GCS and shock index, and non-vehicular injury mechanism (Table 4). Within the derivation cohort, the AUROC of the model was 0.74 (95\% CI 0.69-0.79). After conversion to a score (Table 4), the AUROC was

Table 3 Demographic, injury, and resuscitation characteristics of derivation and validation cohorts

\begin{tabular}{|c|c|c|c|c|}
\hline \multirow[b]{2}{*}{ Age } & \multicolumn{2}{|c|}{$\begin{array}{l}\text { Derivation cohort } \\
(n=1963)\end{array}$} & \multicolumn{2}{|c|}{$\begin{array}{l}\text { Validation cohort } \\
(n=285)\end{array}$} \\
\hline & 44.6 & $(18.5)$ & 48.2 & $(19.0)$ \\
\hline Male sex & 1422 & $(72.6)$ & 204 & (71.6) \\
\hline Non-white race & 349 & $(18.1)$ & 40 & $(14.0)$ \\
\hline Hispanic & 199 & $(10.3)$ & 18 & $(6.4)$ \\
\hline Minutes from injury to ED arrival & 51 & $(38-70)$ & 56 & $(40-86)$ \\
\hline Blunt injury & 1727 & $(88.0)$ & 285 & $(100)$ \\
\hline \multicolumn{5}{|l|}{ Mechanism of injury } \\
\hline Motor vehicle crash & 642 & $(32.7)$ & 104 & $(36.5)$ \\
\hline Motorcycle crash & 185 & $(9.4)$ & 50 & $(17.6)$ \\
\hline Bicycle crash & 83 & $(4.2)$ & 10 & (3.5) \\
\hline Pedestrian struck & 120 & $(6.1)$ & 51 & $(17.9)$ \\
\hline Fall & 435 & $(22.2)$ & 44 & $(15.4)$ \\
\hline Other & 498 & $(25.4)$ & 26 & (9.1) \\
\hline \multicolumn{5}{|l|}{ First recorded prehospital vital signs } \\
\hline Systolic blood pressure $(\mathrm{mmHg})$ & 131 & (28) & 116 & (37) \\
\hline Heart rate & 94 & (23) & 99 & (26) \\
\hline Respiratory rate & 20 & $(5.3)$ & 19 & (7.6) \\
\hline First recorded non-intubated GCS & 15 & $(13-15)$ & 14 & $(8-15)$ \\
\hline \multicolumn{5}{|l|}{ Pre-hospital interventions } \\
\hline Cardiopulmonary resuscitation & 41 & $(2.1)$ & 9 & $(3.2)$ \\
\hline Chest decompression & 29 & $(1.5)$ & 8 & $(2.8)$ \\
\hline Intubation & 317 & $(16.2)$ & 145 & $(50.9)$ \\
\hline Initial ED temperature & 36.3 & $(1.07)$ & 35.9 & $(1.23)$ \\
\hline Injury severity score & 17.3 & $(12.0)$ & 32.3 & $(15.1)$ \\
\hline Admission INR & 1.19 & $(0.74)$ & 1.25 & $(0.26)$ \\
\hline Acute traumatic coagulopathy & 115 & $(5.9)$ & 26 & $(9.1)$ \\
\hline Death before discharge & 175 & (8.9) & 37 & $(13.0)$ \\
\hline
\end{tabular}

Values reported as median (SD), number (\%) or median (IQR). ED emergency department, GCS Glasgow Coma Score, INR international normalized ratio unchanged (0.74, 95\% CI 0.69-0.79). Internal validation using bootstrap methods estimated that predictive optimism contributed 0.02 (95\% CI $-0.03-0.08)$ to the measured AUROC, resulting in an optimism-adjusted AUROC of 0.72 (95\% CI 0.66-0.78). The HosmerLemeshow goodness-of-fit test demonstrated no evidence for inadequate model fit $\left(\chi_{\mathrm{df}=5}, 2.82, p=0.73\right)$. An interactive PACT score calculator is available online at www.pactscore.com [51].

Application of the PACT score to the independent validation cohort yielded an AUROC of 0.80 (95\% CI $0.72-$ 0.88). The PACT score AUROC was significantly greater than the COAST score AUROC $(0.70,95 \%$ CI $0.60-0.80$, $p=0.032$ for comparison; Fig. 1). Including PTT $>60 \mathrm{sec}-$ onds in the definition of ATC yielded similar results (AUROC 0.80 vs. $0.71, p=0.038$ ). There was no statistical evidence of inadequate calibration for either the PACT score (Hosmer-Lemeshow goodness-of-fit statistic $\left.\mathrm{X}_{\mathrm{df}=7}=4.02, p=0.77\right)$, or the COAST score $\left(\mathrm{X}_{\mathrm{df}=7}=11.25\right.$, $p=0.13$ ). However, graphical evaluation suggested good calibration of the PACT score but an inconsistent relationship between observed and predicted ATC risk at higher COAST score values (Fig. 2). Dividing the PACT score into deciles rather than seven quantiles of predicted risk did not alter these conclusions $\left(\chi_{\mathrm{df}=10}=8.30\right.$, $p=0.59$ ).

Setting the PACT score cutoff at $\geq 196$ maximized sensitivity and specificity at $73.1 \%$ and $73.8 \%$, respectively (Table 5). Applying this threshold to the validation cohort, 191 of 198 patients (96.5\%) with a PACT score $<196$ were correctly identified as not having coagulopathy. Among those with a positive PACT score, 19 of 87 (21.8\%) had coagulopathy. At the COAST score recommended threshold of $\geq 3$, sensitivity was $26.9 \%$ and specificity was $86.1 \%$. Of 43 COAST scores $\geq 3,36$ (84.7\%) were false positives (Table 5 ).

\section{Discussion}

We developed and externally validated a model predicting ATC prior to ED arrival in patients with severe trauma. The PACT score, incorporating a small number of objective and readily measured data elements routinely available to prehospital providers, exhibited good discrimination and calibration when tested in an independent trauma cohort and performed better in both domains than the only previously published prehospital ATC prediction tool.

Benefits of prehospital identification, expedited triage, and receiving hospital notification are well-recognized for conditions where time to treatment affects outcomes $[31,52,53]$. Given the time course of exsanguinationrelated mortality and the early separation of survival curves for patients with and without ATC, the best time to intervene in ATC appears to be within minutes of 
Table 4 Majority rules model selection results and final Prediction of Acute Coagulopathy of Trauma (PACT) score

\begin{tabular}{|c|c|c|c|c|c|c|c|}
\hline Variable & $\begin{array}{l}\text { Models containing } \\
\text { candidate predictor }\end{array}$ & $\begin{array}{l}\text { In final } \\
\text { prediction } \\
\text { model? }\end{array}$ & $\begin{array}{l}\text { Regression } \\
\text { coefficient }\end{array}$ & SE & $\begin{array}{l}\text { Standardized } \\
\text { regression } \\
\text { coefficient }^{\mathrm{a}}\end{array}$ & Value & $\begin{array}{l}\text { Points } \\
\text { per unit }\end{array}$ \\
\hline First prehospital shock index $\geq 1$ & Forced into model & Yes & 0.933 & 0.249 & 0.324 & Yes/no & 90 \\
\hline Age & $100 \%$ & Yes & 0.0119 & 0.006 & 0.275 & $\begin{array}{l}\text { Age, rounded to } \\
\text { nearest decade }\end{array}$ & 1 \\
\hline $\begin{array}{l}\text { Mechanism of injury not motor } \\
\text { vehicle, motorcycle, or bicycle crash }\end{array}$ & $100 \%$ & Yes & 0.514 & 0.215 & 0.256 & Yes/no & 50 \\
\hline Number of GCS points below 15 & $98 \%$ & Yes & 0.0705 & 0.032 & 0.171 & $15-$ GCS & 7 \\
\hline Prehospital CPR & $100 \%$ & Yes & 1.198 & 0.461 & 0.188 & Yes/no & 120 \\
\hline $\begin{array}{l}\text { Prehospital intubation or advanced } \\
\text { airway }\end{array}$ & $74 \%$ & Yes & 0.510 & 0.315 & 0.219 & Yes/no & 50 \\
\hline Prehospital chest decompression & $0 \%$ & No & - & - & - & - & - \\
\hline $\begin{array}{l}\text { Time from injury to emergency } \\
\text { department }\end{array}$ & $6 \%$ & No & - & - & - & - & - \\
\hline Constant & N/A & Yes & -4.256 & 0.334 & - & - & - \\
\hline
\end{tabular}

${ }^{a}$ Standardized regression coefficients represent the change in the log-odds of acute traumatic coagulopathy for a 1 standard deviation increase in the value of the predictor. CPR cardiopulmonary resuscitation, GCS Glasgow Coma Score, N/A not applicable

injury [14, 54]. We created the PACT score in response to calls for improved ATC recognition within this window of opportunity $[55,56]$. The implementation of the score in clinical care must await clinical trials of PACT score-guided therapy. In the meantime, stratification of trauma patients according to ATC risk using the PACT score could aid study of this condition's mechanisms and facilitate interventional trials of its treatment. Enrolling patients at high risk of ATC would foster efficient resource use, reduce heterogeneity, and enrich cohorts with the subjects most likely to benefit from a particular treatment, thereby increasing study power.

The PACT score demonstrated good ability to discriminate patients with ATC. Discrimination improved in the

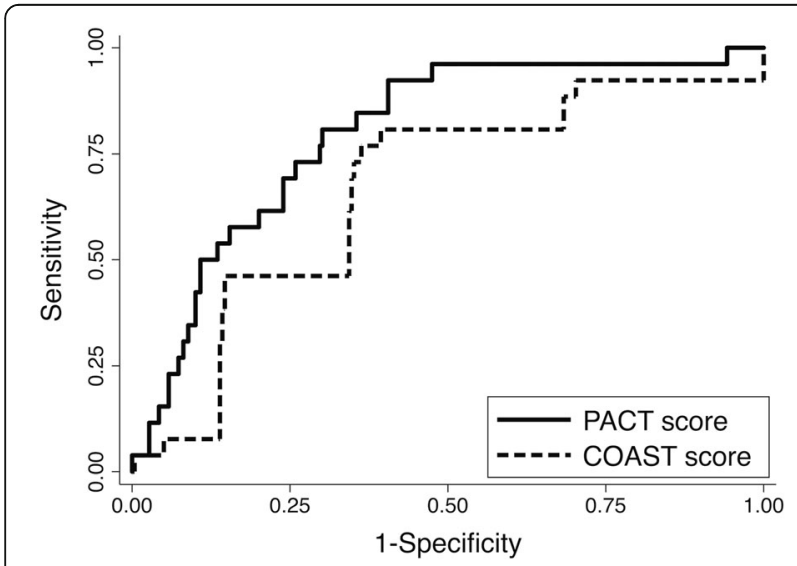

Fig. 1 Discrimination of prehospital acute traumatic coagulopathy prediction scores. Prediction of Acute Coagulopathy of Trauma (PACT) score area under the receiver operating characteristic curve 0.80 (95\% Cl 0.72-0.88) in the validation cohort vs. 0.68 (95\% Cl 0.60-0.80) for the Coagulopathy of Severe Trauma (COAST) score $(p=0.038)$ validation cohort compared to the derivation cohort, suggesting the score has better accuracy in patients who are sicker and/or suffered blunt injury. The PACT score cannot, however, diagnose ATC with perfect accuracy and would benefit from testing against physician judgment. Clinical application therefore largely awaits studies investigating targeted prehospital or "ED doorway" therapies. The appropriate PACT score cutoff will, moreover, depend on the specific application. In a low-prevalence environment, a PACT score $\geq 160$ (92\% sensitivity, 59\% specificity) could guide treatment selection for low-risk interventions. Alternatively, for a theoretical study recruiting high-risk patients from the validation cohort, a PACT score $\geq 250$ would enroll 38 patients of whom $29 \%$ would have ATC. This compares favorably with the COAST score at its recommended threshold (27 subjects, 19\% ATC) or unselected enrollment (285 subjects, 9\% ATC).

Viscoelastic assays deliver partial results within 10-15 minutes of test initiation, allowing attractively rapid post-admission coagulopathy evaluation at the minority of level 1 trauma centers where these assays are available $[57,58]$. However, startup costs, assay system interchangeability and reliability issues, and particularly the absence of a consensus outcome-linked viscoelastic ATC definition pose barriers to the application of viscoelastic assays in clinical care and research outside high-volume, high-resource trauma centers [20, 57, 59, 60]. Because the PACT score accelerates ATC risk stratification relative to viscoelastic assays and is applicable in the settings without access to these tests where most trauma patients receive their initial care, we believe the PACT score has a role in ATC research and, eventually, in clinical care. 


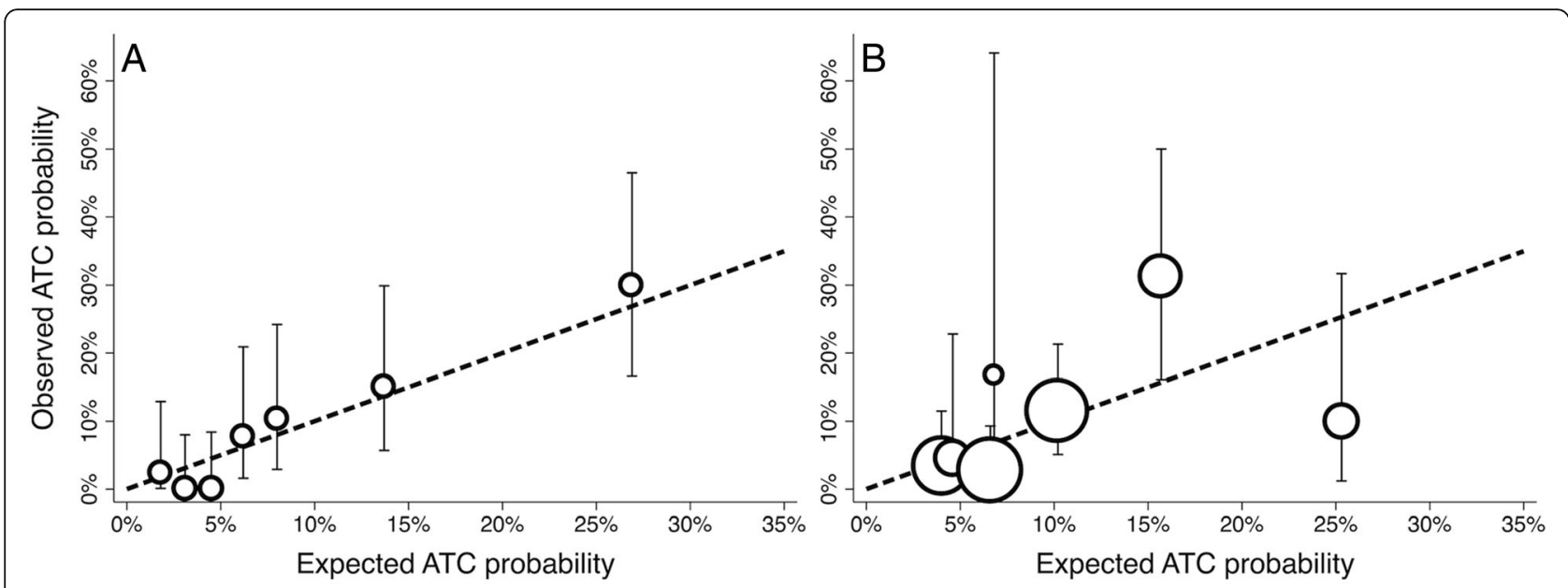

Fig. 2 Calibration of prehospital acute traumatic coagulopathy prediction scores in the validation cohort. Observed acute traumatic coagulopathy (ATC) probability vs. risk predicted by the Prediction of Acute Coagulopathy of Trauma (PACT) score (a) and Coagulopathy of Severe Trauma (COAST) score (b). Circles, proportional to subjects represented, indicate actual score (COAST) or $1 / 7^{\text {th }}$ quantiles of predicted risk (PACT). Error bars represent $95 \%$ confidence intervals for observed ATC probabilities

Table 5 Operating characteristics of the Prediction of Acute Coagulopathy of Trauma (PACT) score in the validation cohort

\begin{tabular}{|c|c|c|c|c|c|}
\hline PACT score & $\geq 100$ & $\geq 150$ & $\geq 200$ & $\geq 250$ & $\geq 300$ \\
\hline \multicolumn{6}{|l|}{ Patients } \\
\hline True positive & 25 & 25 & 18 & 11 & 3 \\
\hline False positive & 186 & 125 & 67 & 27 & 9 \\
\hline True negative & 73 & 134 & 192 & 232 & 250 \\
\hline False negative & 1 & 1 & 8 & 15 & 23 \\
\hline \multicolumn{6}{|l|}{ Operating characteristics } \\
\hline Sensitivity (\%) & 96.2 & 96.2 & 69.2 & 42.3 & 11.5 \\
\hline Specificity (\%) & 28.2 & 51.7 & 74.1 & 89.6 & 96.5 \\
\hline Positive likelihood ratio & 1.34 & 1.99 & 2.68 & 4.06 & 3.32 \\
\hline Negative likelihood ratio & 0.14 & 0.07 & 0.42 & 0.64 & 0.92 \\
\hline COAST score & $\geq 1$ & $\geq 2$ & $\geq 3$ & $\geq 4$ & $\geq 5$ \\
\hline \multicolumn{6}{|l|}{ Patients } \\
\hline True positive & 23 & 15 & 7 & 1 & 0 \\
\hline False positive & 177 & 89 & 36 & 2 & 0 \\
\hline True negative & 82 & 170 & 223 & 257 & 259 \\
\hline False negative & 3 & 11 & 19 & 25 & 26 \\
\hline \multicolumn{6}{|l|}{ Operating characteristics } \\
\hline Sensitivity (\%) & 88.5 & 57.7 & 26.9 & 3.9 & 0 \\
\hline Specificity (\%) & 31.7 & 65.6 & 86.1 & 99.3 & 100 \\
\hline Positive likelihood ratio & 1.29 & 1.68 & 1.94 & 4.98 & - \\
\hline Negative likelihood ratio & 0.36 & 0.64 & 0.85 & 0.97 & 1 \\
\hline
\end{tabular}

PACT score Prediction of Acute Coagulopathy of Trauma score, COAST score Coagulopathy of Severe Trauma score
Consistent with previous studies, patients with ATC had substantially increased mortality. Higher ATC mortality in the less severely injured derivation cohort may reflect differences in timing of cohort entry or outcome variation between a multilevel trauma system and a single high-volume level 1 trauma center [61]. Overall, variables in our model indicate greater injury relative to physiologic reserve, in line with prior research correlating ATC prevalence with injury severity and hypoperfusion $[13,62]$. Besides suggesting particularly severe injury, the predictive utility of prehospital CPR may also signal a contribution from the type of coagulopathy previously observed in survivors of non-traumatic cardiac arrest [63]. However, this study was not designed to identify ATC risk factors and our results should not be interpreted as evidence of causal associations between the studied predictors and ATC.

Our study strengths include an independent cohort for external model validation, sufficient events per variable tested, and a model selection algorithm balancing the predictive utility of the variables against the risk of overfitting. Whereas complete case analysis would have limited our effective sample size and introduced bias into model development and evaluation [36, 64], our approach using multiple imputation to manage missing data avoided excluding patients with missing predictor values and has been widely recommended in recent literature on predictive models $[36,50,64]$. We nevertheless cannot exclude residual bias due to missing predictor or outcome data.

The COAST score calculation required several approximations due to differences between its derivation dataset and our datasets. We estimated prehospital temperature using a validated extrapolation and applied the original 
manuscript surrogate for prehospital providers' subjective abdominal/pelvic injury evaluation [22, 33]. These modifications may have penalized the COAST score in comparisons with the PACT score.

In parallel to past studies [22], we focused on severely injured patients in order to create a tool for stratifying among patients at risk of ATC rather than for screening unselected trauma patients for ATC. Selection of severely injured patients for both cohorts, however, relied on retrospective application of severity markers and other data available only after hospital admission. Though parallel in this respect to the procedures applied for development and validation of the COAST score [22] and a well-known prediction model for massive transfusion $[65,66]$, cohort selection for prehospital prediction model building and testing would ideally use prehospital data. The PACT score may perform differently if applied to patients identified as severely injured solely from information available prehospital or upon ED arrival.

Our study has several additional limitations. We defined ATC as an INR $>1.5$ on hospital admission, a validated definition [17] which may nevertheless not capture all mechanisms - including hyperfibrinolysis relevant to the impact of the syndrome on trauma outcomes. Substituting the ATC definition employed by Mitra et al. (INR $>1.5$ or PTT $>60$ seconds) did not alter our results. As we were unable to exclude subjects with liver disease, the derangement of INR in some subjects may have resulted from preexisting conditions.

The model derivation cohort was less severely injured and, as a result, had less physiologic derangement and lower mortality than the validation cohort. Compared to model evaluation in an identically defined cohort, the two cohorts' entry criteria and mortality actually provided a more rigorous generalizability test. Global variations in injury patterns and prehospital care could decrease the accuracy of our prediction model outside of North America. Finally, the lower-than-expected ATC incidence in the validation cohort yielded a suboptimal sample size for model validation [67]. Though it represents one of the few validated prediction tools, repeating the PACT score validation in a larger, more diverse trauma cohort identified from prehospital criteria would be useful to further confirm its generalizability.

\section{Conclusions}

In conclusion, we report derivation and external validation of a prediction model that employs objective, routinely collected prehospital data to identify patients at increased risk of ATC. The PACT score exhibited improved discrimination and calibration relative to a previously reported ATC prediction model. Application of the PACT score during study recruitment could aid therapeutic trials by enriching enrolled cohorts with the patients most likely to benefit from treatments targeting coagulopathy.

\section{Additional files}

Additional file 1: Table S1. Data missingness for candidate ATC predictors and variables (both missing and non-missing covariates) included in multiple imputation model. (PDF 42 kb)

Additional file 2: Figure S1. Schematic diagram of "majority rules" algorithm for selection of a parsimonious prediction model in multiply imputed data. (PDF $347 \mathrm{~kb}$ )

Additional file 3: Figures S2 and S3. Subject enrollment flow diagrams for cohorts employed in model deviation and validation. (PDF 781 kb)

\section{Abbreviations}

AIS: abbreviated injury score; ATC: acute traumatic coagulopathy; AUROC: area under the receiver operator characteristic curve; COAST score: Coagulopathy of Severe Trauma score; ED: emergency department; GCS: Glasgow Coma Score; ICU: intensive care unit; INR: international normalized ratio; ISS: injury severity score; PACT score: Prediction of Acute Coagulopathy of Trauma score; PTT: partial thromboplastin time; SBP: systolic blood pressure

\section{Acknowledgements}

The authors wish to thank the staff of the Oregon Trauma Registry for providing access to data and the members of the Pulmonary/Critical Care Clinical Research Works-in-Progress seminar at the University of Washington for thoughtful feedback on the design and analysis of this study.

\section{Funding}

This study was supported by training grant T32 HL728735 (IDP), career development grant K23 GM086729 (TRW, EC), and clinical and translational sciences award UL1TR000423 (University of Washington) from the National Institutes of Health, which had no role in study design, data collection, analysis or interpretation, or manuscript preparation.

\section{Availability of data and materials}

The derivation cohort dataset supporting the conclusions of this article is available by application to the Oregon Health Authority after approval by the appropriate ethics committees. The validation cohort dataset supporting the conclusions of this article is available, after ethics committee approval, from Dr. Lisa Vande Vusse, the custodian of the dataset from the Age of Transfused Blood and Lung Injury After Trauma Study.

\section{Authors' contributions}

IDP and TRW conceived the study. IDP, TRW, RVM, TDR, ARR, and LKW participated in study design. EC, IDP, TRW, and LKW participated in data collection. EC and IDP processed data. IDP, TRW, TDR, ARR, and LKW designed the statistical analyses. IDP performed statistical analyses. IDP drafted the manuscript. All authors read, revised, and approved the final manuscript.

\section{Competing interests}

Dr. Watkins is currently employed by Gilead Sciences, which is not involved in commercial research relevant to this work. The remaining authors declare that they have no competing interests.

\section{Consent for publication}

Not applicable.

\section{Ethics approval and consent to participate}

The Oregon Health Authority and University of Washington Institutional Review Boards approved use of Oregon Trauma Registry data and granted a waiver of informed consent for retrospective data analysis. Subjects provided informed consent to participate in the observational Age of Transfused Blood and Lung Injury After Trauma Study under a protocol approved by the University of Washington Institutional Review Board, which subsequently granted exempt status to the current secondary analysis. 


\section{Author details}

'Division of Pulmonary and Critical Care Medicine, Department of Medicine, University of Washington School of Medicine, 1959 NE Pacific St, Box 356522, Seattle, WA 98195, USA. ${ }^{2}$ Division of Pulmonary and Critical Care Medicine, Department of Medicine, Intermountain Medical Center, Salt Lake City, UT, USA. ${ }^{3}$ Division of Pulmonary and Critical Care Medicine, Department of Medicine, University of Utah School of Medicine, Salt Lake City, UT, USA. ${ }^{4}$ Department of Epidemiology, University of Washington School of Public Health, Seattle, WA, USA. ${ }^{5}$ Department of Medicine, University of Washington School of Medicine, Seattle, WA, USA. ${ }^{6}$ Department of Surgery, University of Washington School of Medicine, Seattle, WA, USA.

Received: 30 August 2016 Accepted: 20 October 2016 Published online: 16 November 2016

\section{References}

1. Van den Berghe G, Wilmer A, Hermans G, Meersseman W, Wouters PJ, Milants I, et al. Intensive insulin therapy in the medical ICU. New Engl J Med. 2006;354:449-61.

2. Perner A, Haase N, Guttormsen AB, Tenhunen J, Klemenzson G, Åneman A et al. Hydroxyethyl starch 130/0.42 versus Ringer's acetate in severe sepsis. New Engl J Med. 2012;367:124-34.

3. Ranieri VM, Thompson BT, Barie PS, Dhainaut J-F, Douglas IS, Finfer S, et al. Drotrecogin alfa (activated) in adults with septic shock. New Engl J Med. 2012;366:2055-64.

4. Angus DC, Barnato AE, Bell D, Bellomo R, Chong CR, Coats TJ, et al. A systematic review and meta-analysis of early goal-directed therapy for septic shock: the ARISE, ProCESS and ProMISe Investigators. Int Care Med. 2015;41:1549-60.

5. National Center for Injury Prevention and Control. 10 Leading Causes of Death by Age Group, United States - 2013. Centers for Disease Control 2014. Available at http://www.cdc.gov/injury/wisqars/pdf/leading_causes_ of_death_by_age_group_2013-a.pdf. Accessed 9 Feb 2016.

6. Evans JA, van Wessem KJP, McDougall D, Lee KA, Lyons T, Balogh ZJ. Epidemiology of traumatic deaths: comprehensive population-based assessment. World J Surg. 2010;34:158-63.

7. Boffard KD, Riou B, Warren B, Choong PIT, Rizoli S, Rossaint R, et al. Recombinant factor Vlla as adjunctive therapy for bleeding control in severely injured trauma patients: two parallel randomized, placebo-controlled, double-blind clinical trials. J Trauma. 2005;59:8-15. Discussion 15-8.

8. Hauser CJ, Boffard K, Dutton R, Bernard GR, Croce MA, Holcomb JB, et al. Results of the CONTROL trial: efficacy and safety of recombinant activated Factor VII in the management of refractory traumatic hemorrhage. J Trauma. 2010:69:489-500

9. Yank V, Tuohy CV, Logan AC, Bravata DM, Staudenmayer K, Eisenhut R, et al. Systematic review: benefits and harms of in-hospital use of recombinant factor VIla for off-label indications. Ann Intern Med. 2011;154:529-40.

10. Holcomb JB, Tilley BC, Baraniuk S, Fox EE, Wade CE, Podbielski JM, et al. Transfusion of plasma, platelets, and red blood cells in a 1:1:1 vs a 1:1:2 ratio and mortality in patients with severe trauma: The PROPPR randomized clinical trial. JAMA. 2015;313:471-82.

11. Vincent J-L. We should abandon randomized controlled trials in the intensive care unit. Crit Care Med. 2010;38:S534-8.

12. Prescott HC, Calfee CS, Thompson BT, Angus DC, Liu VX. Toward smarter lumping and smarter splitting: rethinking strategies for sepsis and acute respiratory distress syndrome clinical trial design. Am J Respir Crit Care Med. 2016:194:147-55.

13. Brohi K, Singh J, Heron M, Coats T. Acute traumatic coagulopathy. J Trauma. 2003;54:1127-30.

14. MacLeod JBA, Lynn M, McKenney MG, Cohn SM, Murtha M. Early coagulopathy predicts mortality in trauma. J Trauma. 2003;55:39-44.

15. Davenport R, Manson J, De'Ath H, Platton S, Coates A, Allard S, et al. Functional definition and characterization of acute traumatic coagulopathy. Crit Care Med. 2011;39:2652-8.

16. Cohen MJ, Call M, Nelson M, Calfee CS, Esmon CT, Brohi K, et al. Critical role of activated protein $\mathrm{C}$ in early coagulopathy and later organ failure, infection and death in trauma patients. Ann Surg. 2012;255:379-85.

17. Peltan ID, Vande Vusse LK, Maier RV, Watkins TR. An international normalized ratio-based definition of acute traumatic coagulopathy is associated with mortality, venous thromboembolism, and multiple organ failure after injury. Crit Care Med. 2015;43:1429-38.
18. David JS, Levrat A, Inaba K, Macabeo C, Rugeri L, Fontaine O, et al. Utility of a point-of-care device for rapid determination of prothrombin time in trauma patients. J Trauma Acute Care Surg. 2012;72:703-7.

19. da Luz LT, Nascimento B, Rizoli S. Thrombelastography (TEG $\left.{ }^{\oplus}\right)$ : practical considerations on its clinical use in trauma resuscitation. Scand J Trauma Resusc Emerg Med. 2013;21:1-8.

20. Hagemo JS, Næss PA, Johansson P, Windeløv NA, Cohen MJ, Røislien J, et al. Evaluation of TEG ${ }^{\oplus}$ and RoTEM $^{\circledast}$ inter-changeability in trauma patients. Injury. 2013;44:600-5.

21. Hunt H, Stanworth S, Curry N, Woolley T, Cooper C, Ukoumunne O, et al. Thromboelastography (TEG) and rotational thromboelastometry (ROTEM) for trauma-induced coagulopathy in adult trauma patients with bleeding. Cochrane Database Syst Rev. 2015;2:CD010438.

22. Mitra B, Cameron PA, Mori A, Maini A, Fitzgerald M, Paul E, et al. Early prediction of acute traumatic coagulopathy. Resuscitation. 2011;82:1208-13.

23. Steyerberg EW, Vickers AJ, Cook NR, Gerds T, Gonen M, Obuchowski N, et al. Assessing the performance of prediction models: A framework for traditional and novel measures. Epidemiology. 2010;21:128-38.

24. Emergency Medical Services and Trauma Systems Data Unit. Oregon Trauma Registry 2003-2012 Report. Oregon Health Authority 2014. Available at https:// public.health.oregon.gov/ProviderPartnerResources/EMSTraumaSystems/ TraumaSystems/Documents/reports/otr-report.pdf. Accessed 21 Aug 2015

25. Emergency Medical Services and Trauma Systems Data Unit. Oregon Trauma Registry Data Dictionary. Oregon Health Authority 2013. Available at https://public.health.oregon.gov/ProviderPartnerResources/

EMSTraumaSystems/TraumaSystems/Documents/2013/Abstract_Manual_ Version_19.pdf. Accessed 15 July 2015.

26. Maegele M, Schöchl H, Cohen MJ. An update on the coagulopathy of trauma. Shock. 2014;41 Suppl 1:21-5.

27. Vande Vusse LK, Caldwell E, Tran E, Hogl L, Dinwiddie S, López JA, et al. The epidemiology of transfusion-related acute lung injury varies according to the applied definition of lung injury onset time. Ann Am Thorac Soc. 2015;12:1238-335

28. Arbabi S, Jurkovich GJ, Wahl WL, Franklin GA, Hemmila MR, Taheri PA, et al. A comparison of prehospital and hospital data in trauma patients. J Trauma. 2004:56:1029-32.

29. King RW, Plewa MC, Buderer NM, Knotts FB. Shock index as a marker for significant injury in trauma patients. Acad Emerg Med. 1996;3:1041-5.

30. Baker SP, O'Neill B, Haddon W, Long WB. The injury severity score: a method for describing patients with multiple injuries and evaluating emergency care. J Trauma. 1974;14:187-96.

31. Sasser SM, Hunt RC, Faul M, Sugerman D, Pearson WS, Dulski T, et al. Guidelines for field triage of injured patients: recommendations of the National Expert Panel on Field Triage, 2011. MMWR Recomm Rep. 2012;61:1-20.

32. National Trauma Data Bank. National Trauma Data Standard Data Dictionary: 2015 Admissions. American College of Surgeons 2015. Available at http:// www.ntdsdictionary.org/dataElements/documents/NTDSDataDictionary2015Admissions_040215.pdf. Accessed 24 Sept 2015

33. Carleton E, Fry B, Mulligan A, Bell A, Brossart C. Temporal artery thermometer use in the prehospital setting. CJEM. 2012;14:7-13.

34. White IR, Royston P, Wood AM. Multiple imputation using chained equations: Issues and guidance for practice. Stat Med. 2010;30:377-99.

35. Van der Heijden GJMG, Donders ART, Stijnen T, Moons KGM. Imputation of missing values is superior to complete case analysis and the missingindicator method in multivariable diagnostic research: A clinical example. J Clin Epidemiol. 2006;59:1102-9.

36. Steyerberg EW. Clinical Prediction Models: A Practical Approach to Development, Validation, and Updating. New York: Springer; 2009.

37. Little RJA. Missing data adjustments in large surveys. J Bus Econ Stat. 1988;6:287-96.

38. Moons KGM, Donders RART, Stijnen T, Harrell Jr FE. Using the outcome for imputation of missing predictor values was preferred. J Clin Epidemiol. 2006;59:1092-101.

39. Peduzzi P, Concato J, Kemper E, Holford TR, Feinstein AR. A simulation study of the number of events per variable in logistic regression analysis. J Clin Epidemiol. 1996;49:1373-9.

40. Harrell FE, Lee KL, Matchar DB, Reichert TA. Regression models for prognostic prediction: advantages, problems, and suggested solutions. Cancer Treat Rep. 1985;69:1071-7.

41. Vergouwe Y, Royston P, Moons KGM, Altman DG. Development and validation of a prediction model with missing predictor data: a practical approach. J Clin Epidemiol. 2010;63:205-14. 
42. Furnival GM, Wilson RW. Regressions by leaps and bounds. Technometrics. 1974;16:499-511.

43. Lawless JF, Singhal K. Efficient screening of nonnormal regression models. Biometrics. 1978:34:318-27.

44. Lindsey C, Sheather S. Variable selection in linear regression. Stata J. 2010;10:650-69.

45. Akaike $\mathrm{H}$. Information Theory and an Extension of the Maximum Likelihood Principle. In: Parzen E, Tanabe K, Kitagawa G, eds. Selected Papers of Hirotugu Akaike. New York: Springer; 1998. pp. 199-213.

46. Rubin DB. Inference and missing data. Biometrika. 1976;63:581-92.

47. Steyerberg EW, Harrell FE, Borsboom GJ, Eijkemans MJ, Vergouwe Y, Habbema JD. Internal validation of predictive models: efficiency of some procedures for logistic regression analysis. J Clin Epidemiol. 2001;54:774-81.

48. DeLong ER, DeLong DM, Clarke-Pearson DL. Comparing the areas under two or more correlated receiver operating characteristic curves: a nonparametric approach. Biometrics. 1988:44:837-45.

49. Hosmer DW, Lemeshow S. Applied Logistic Regression. New York: Wiley; 1989.

50. Moons KGM, Altman DG, Reitsma JB, loannidis JPA, Macaskill P, Steyerberg EW, et al. Transparent reporting of a multivariable prediction model for individual prognosis or diagnosis (TRIPOD): explanation and elaboration. Ann Intern Med. 2015;162:W1-W73.

51. Peltan ID. Prediction of Acute Traumatic Coagulopathy Score. PACT Score 2015. Available at http://www.pactscore.com. Accessed 9 May 2016

52. European Myocardial Infarction Project Group. Prehospital thrombolytic therapy in patients with suspected acute myocardial infarction. New Engl J Med. 1993;329:383-9.

53. Kim SK, Lee SY, Bae HJ, Lee YS, Kim SY, Kang MJ, et al. Pre-hospital notification reduced the door-to-needle time for IV tPA in acute ischaemic stroke. Eur J Neurol. 2009;16:1331-5.

54. Spahn DR, Bouillon B, Cerny V, Coats TJ, Duranteau J, Fernández-Mondéjar

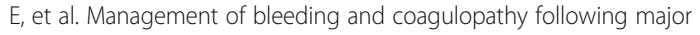
trauma: an updated European guideline. Crit Care. 2013;17:R76.

55. Brohi K. Prediction of acute traumatic coagulopathy and massive transfusion - is this the best we can do? Resuscitation. 2011;82:1128-9.

56. Maegele M, Brockamp T, Nienaber U, Probst C, Schoechl H, Görlinger K, et al. Predictive models and algorithms for the need of transfusion including massive transfusion in severely injured patients. Transfus Med Hemother. 2012;39:85-97.

57. Inaba K, Rizoli S, Veigas PV, Callum J, Davenport R, Hess J, et al. 2014 Consensus conference on viscoelastic test-based transfusion guidelines for early trauma resuscitation: Report of the panel. J Trauma Acute Care Surg. 2015;78:1220-9.

58. Camazine MN, Hemmila MR, Leonard JC, Jacobs RA, Horst JA, Kozar RA, et al. Massive transfusion policies at trauma centers participating in the American College of Surgeons Trauma Quality Improvement Program. J Trauma Acute Care Surg. 2015;78:S48-53.

59. Kitchen DP, Kitchen S, Jennings I, Woods T, Walker I. Quality assurance and quality control of thrombelastography and rotational thromboelastometry: the UK NEQAS for blood coagulation experience. Semin Thromb Hemost. 2010;36:757-63.

60. Peltan ID, Watkins TR. Fibrinogen measurement and viscoelastic technique are necessary to define acute traumatic coagulopathy - the authors reply. Crit Care Med. 2016;44:e106-7.

61. Demetriades D, Martin M, Salim A, Rhee P, Brown C, Doucet J, et al. Relationship between American College of Surgeons trauma center designation and mortality in patients with severe trauma (injury severity score > 15). J Am Coll Surg. 2006;202:212-5.

62. Frith D, Goslings JC, Gaarder C, Maegele M, Cohen MJ, Allard S, et al. Definition and drivers of acute traumatic coagulopathy: clinical and experimental investigations. J Thromb Haemost. 2010;8:1919-25.

63. Adrie C, Monchi M, Laurent I, Um S, Yan SB, Thuong M, et al. Coagulopathy after successful cardiopulmonary resuscitation following cardiac arrest: implication of the protein C anticoagulant pathway. J Am Coll Cardiol. 2005;46:21-8.

64. Janssen KJM, Vergouwe Y, Donders ART, Harrell FE, Chen Q, Grobbee DE, et al. Dealing with missing predictor values when applying clinical prediction models. Clin Chem. 2009;55:994-1001.

65. Nunez TC, Voskresensky IV, Dossett LA, Shinall R, Dutton WD, Cotton BA. Early prediction of massive transfusion in trauma: simple as $A B C$ (assessment of blood consumption)? J Trauma. 2009;66:346-52.
66. Cotton BA, Dossett LA, Haut ER, Shafi S, Nunez TC, Au BK, et al. Multicenter validation of a simplified score to predict massive transfusion in trauma. J Trauma. 2010;69:S33-9.

67. Vergouwe Y, Steyerberg EW, Eijkemans MJC, Habbema JDF. Substantial effective sample sizes were required for external validation studies of predictive logistic regression models. J Clin Epidemiol. 2005;58:475-83.

\section{Submit your next manuscript to BioMed Central and we will help you at every step:}

- We accept pre-submission inquiries

- Our selector tool helps you to find the most relevant journal

- We provide round the clock customer support

- Convenient online submission

- Thorough peer review

- Inclusion in PubMed and all major indexing services

- Maximum visibility for your research

Submit your manuscript at www.biomedcentral.com/submit 